\title{
Stability of an Electric Vehicle with Permanent-Magnet In-Wheel Motors during Electrical Faults
}

\author{
Mats Jonasson* and Oskar Wallmark**
}

\begin{abstract}
This paper presents an analysis of the stability of an electric vehicle equipped with in-wheel motors of permanent-magnet type during a class of electrical faults. Due to the constant excitation from the permanent magnets, the output torque from a faulted wheel cannot easily be removed if an inverter shuts down, which directly affects the vehicle stability. In this paper, the impact of an electrical fault during two driving scenarios is investigated by simulations; using parameters from a $30 \mathrm{~kW}$ in-wheel motor and experimentally obtained tire data. It is shown that the electrical fault risks to seriously degrading the vehicle stability if the correct counteraction is not taken quickly. However, it is also demonstrated that vehicle stability during an electrical fault can be maintained with only minor lateral displacements when a closed-loop path controller and a simple method to allocate the individual tire forces are used. This inherent capacity to handle an important class of electrical faults is attractive; especially since no additional fault-handling strategy or hardware is needed.
\end{abstract}

Keywords: Control system, electrical failure, inverter, in-wheel motor, permanent-magnet motor.

\section{INTRODUCTION}

Adopting in-wheel motors in electric vehicles offers possible benefits in terms of vehicle styling and modularization since the powertrain is kept inside the wheels. Torque actuation can quickly be individually delivered to each wheel, which enables improvements in vehicle stability. Naturally, the study of longitudinal tire-force distribution and yaw control are important aspects for such vehicles as exemplified in [1]-[5]. Due to their high efficiency and torque-to-inertia ratio, permanent-magnet synchronous motors (PMSMs) are suitable candidates for vehicle propulsion. However, faults, arising either in the PMSM or its corresponding inverter, can be very critical due to the permanent magnetization from the rotor magnets, which cannot be removed. Therefore, a considerable research effort has been put into studying the behavior of PMSMs during various types of faults; examples include [6]-[11].

Though the behavior of a PMSM during electrical faults has been extensively covered, its effect on vehicle stability has not been given equal attention. In [12], the vehicle stability of a rear-driven electric vehicle using two in-wheel motors is investigated when the torque from one of the motors is suddenly removed. However, there is a need for more comprehensive knowledge on fault-mitigation methods and vehicle dynamics during electrical faults for vehicles equipped

* Department of Chassis and Vehicle Dynamics, Volvo Cars Corporation, SE-405 31 Göteborg, Sweden, E-mail: mjonass2@volvocars.com

** Swedish Center of Excellence in Electric Power Engineering $\left(\mathrm{EKC}^{2}\right)$, Royal Inst. of Technology (KTH), SE-100 44 Stockholm, Sweden, E-mail: oskar.wallmark@ee.kth.se with in-wheel motors; particularly when permanent-magnet motors are adopted since they can generate high braking torque if their corresponding inverters shut down when the motor operates at high speeds.

\subsection{Contributions and Outline of Paper}

This paper presents an analysis of the vehicle stability of an electric vehicle equipped with four in-wheel motors during an inverter shutdown in one or two of the inverters individually powering the in-wheel motors. A vehicle simulation model is adopted that uses experimentally obtained tire data. PMSM motors are considered and the generated torque during an inverter shutdown is obtained from an experimental in-wheel PMSM of outer-rotor type.

The vehicle behavior during two fault scenarios is examined assuming constant steering angles and wheel torques; essentially to determine at what time scales the fault scenarios become critical in terms of safety. It is shown that the vehicle, due to the electrical fault, quickly deviates from the intended course.

As a mean of fault mitigation, it is investigated to what extent the adoption of a closed-loop path controller, controlling the remaining in-wheel motors and wheel steering angles, can handle this important class of electrical faults. The results illustrate that the path controller, using a simple rule to allocate tire forces, can handle the faults properly with only minor displacements of the vehicle. This inherent capacity to handle an important class of electrical faults is attractive, especially since no additional fault-handling strategy or complex hardware is 
required.

The paper is outlined as follows. Section 2 describes the adopted vehicle configuration. The dynamic modeling of the vehicle and tires are presented in Section 3. Section 4 reviews the closed-loop path controller presented in [3] and some modifications are proposed. The electrical faults considered are described in Section 5. Finally, the case study and conclusions are presented in Section 6 and 7, respectively.

\section{VEHICLE CONFIGURATION}

The vehicle considered in this study is a small passenger car equipped with four in-wheel motors and developed mainly for urban transport. The in-wheel motors are direct driven, i.e., the rotor is directly connected to the wheel hub; an example of such a motor design is shown in Fig. 1a.

A possible vehicle design exploiting the benefits of using in-wheel motors is shown in Fig. 1b. As seen, the windscreen is lengthened forwards to facilitate visibility. Furthermore, the vehicle is four-wheel steered where all steering angles can be individually controlled by actuators. Chassis composed of in-wheel motors and individual control of the steering angles offer the opportunity to freely distribute the lateral and longitudinal forces on the vehicle which is exemplified in [13], [14].

a)

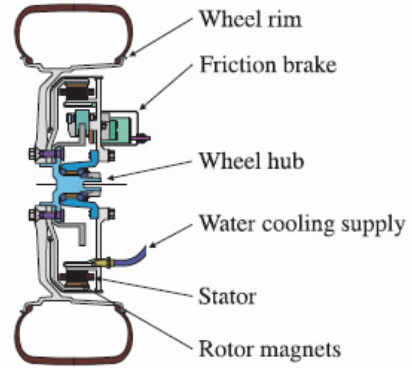

b)
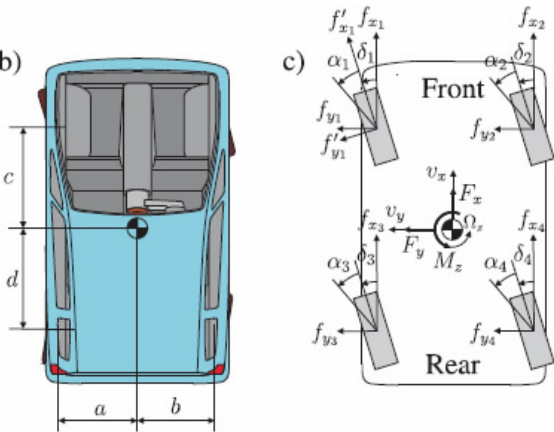

Fig. 1 a) An example of a direct driven in-wheel motor design; b) A possible vehicle design exploiting some benefits of using in-wheel motors; c) Adopted vehicle model showing the global and corner forces. The tire forces are also shown for the front-left wheel.

\section{VEHICLE DYNAMICS}

The influence from a faulted in-wheel motor changes the vehicle yaw moment rather than the roll, pitch and vertical movements. Consequently, the latter effects are assumed to be negligible. However, the lateral acceleration is not insignificant during the fault scenarios and the load transfer, from the inner to the outer wheels, is taken into account to obtain appropriate tire loads. The change in vehicle yaw moment motivates the use of the, well-known, two-track vehicle model governing the longitudinal, lateral, and rotational dynamics. The longitudinal and lateral speeds $\left(v_{x}, v_{y}\right)$ and yaw rate $\left(\Omega_{z}\right)$ are governed by

$$
\mathbf{M} \dot{\mathbf{x}}=\mathbf{h}(\mathbf{x})+\mathbf{u}+\mathbf{v}(\mathbf{x}),
$$

where $\mathbf{x}=\left[\begin{array}{lll}v_{x} & v_{y} & \Omega_{z}\end{array}\right]^{T}$. Also, $\mathbf{u}=\left[\begin{array}{lll}F_{x} & F_{y} & M_{z}\end{array}\right]^{T}$ represents the total longitudinal and lateral forces, and yaw moment acting at the vehicle center of gravity (here termed global forces). Fig. 1c shows how the global forces are related to the individual corner and tire forces. The mass matrix $\mathbf{M}$, coupling terms $\mathbf{h}(\mathbf{x})$ and external forces $\mathbf{v}(\mathbf{x})$ are found as

$$
\begin{gathered}
\mathbf{M}=\operatorname{diag}\left[\begin{array}{lll}
m & m & J_{z}
\end{array}\right]^{T}, \\
\mathbf{h}(\mathbf{x})=m\left[\begin{array}{llll}
x_{2} x_{3} & x_{1} x_{3} & 0
\end{array}\right]^{T}, \\
\mathbf{v}(\mathbf{x})=\left[\begin{array}{lll}
v_{1}\left(x_{1}\right) & 0 & 0
\end{array}\right]^{T},
\end{gathered}
$$

where $m$ and $J_{z}$ are the vehicle mass and yaw inertia, respectively. The air and roll resistance are governed by $v_{1}\left(x_{1}\right)$ which can be expressed as

$$
v_{1}\left(x_{1}\right)=-\frac{C_{\mathrm{d}} A_{\mathrm{f}} \rho_{\text {air }} x_{1}^{2}}{2}-m g f_{\text {roll }},
$$

where $C_{d}$ is the coefficient of $\mathrm{drag}, A_{\mathrm{f}}$ the frontal area, $\rho_{\text {air }}$ the density of air, $g$ the acceleration due to gravity, and $f_{\text {roll }}$ the rolling-resistance coefficient. The global forces, in turn, are related to the individual corner forces $f_{x_{1}}, f_{y_{1}}, \cdots, f_{x_{4}}, f_{y_{4}}$ as $\mathbf{u}=\mathbf{B} \mathbf{u}^{\dagger}$ where

$$
\begin{gathered}
\mathbf{B}=\left(\begin{array}{cccccccc}
1 & 0 & 1 & 0 & 1 & 0 & 1 & 0 \\
0 & 1 & 0 & 1 & 0 & 1 & 0 & 1 \\
-a & c & b & c & -a & -d & b & -d
\end{array}\right), \\
\mathbf{u}^{\dagger}=\left[f_{x_{1}} f_{y_{1}} f_{x_{2}} f_{y_{2}} f_{x_{3}} f_{y_{3}} f_{x_{4}} f_{y_{4}}\right]^{T},
\end{gathered}
$$

and $a, b, c, d$ represent vehicle dimensions as shown in Fig. 1. Finally, the individual tire forces are obtained from the corner forces using the transformation

$$
\left(\begin{array}{l}
f_{x_{i}}^{\prime} \\
f_{y_{i}}^{\prime}
\end{array}\right)=\left(\begin{array}{cc}
\cos \delta_{i} & \sin \delta_{i} \\
-\sin \delta_{i} & \cos \delta_{i}
\end{array}\right)\left(\begin{array}{l}
f_{x_{i}} \\
f_{y_{i}}
\end{array}\right), \mathrm{i}=1,2,3,4,
$$

where $\delta_{i}$ is the steering angle for the $\mathrm{i}$ :th wheel.

\subsection{Tire Modeling}

The tire model must handle the influence of the rapid change in torque from the faulted in-wheel motor correctly. The inherent damping of the tire is taken into account by filtering the output torque from the in-wheel 
motor using a filter with a time constant equal to the time for the wheel to rotate a third of a revolution. Furthermore, the tire model must account for the generation of lateral forces for a wide range of tire slip angles. Therefore, the lateral tire force dependence on the side slip is here governed by a shortened variant of the well-known Magic formula [15]:

$$
f_{y_{i}}^{\prime}=-D_{y_{i}} \sin \left[C_{y} \arctan \left(B_{y_{i}} \alpha_{i}\right)\right], i=1,2,3,4
$$

where the peak value $D_{y_{i}}$, the shape factor $C_{y}$ and the stiffness factor $B_{y_{i}}$ are Magic-formula variables and $\alpha_{i}$ is the tire side-slip angle for the $\mathrm{i}$ :th tire. The peak value and stiffness factor are found as

$$
\begin{gathered}
D_{y_{i}}=\mu_{i} f_{z_{i}}\left[1-\left(\frac{f_{x_{i}}^{\prime}}{\mu_{i} f_{z_{i}}}\right)^{n}\right]^{1 / n}\left(k_{z_{1}}-k_{z_{2}} \frac{f_{z_{i}}-f_{z, \text { nom }}}{f_{z, \text { nom }}}\right),(10 \\
B_{y_{i}}=\frac{C_{F_{\alpha_{i}}}}{C_{y} D_{y_{i}}} \\
C_{F_{\alpha_{i}}}=c_{1} f_{z, \text { nom }} \sin \left[2 \arctan \left(\frac{f_{z_{i}}}{c_{2} f_{z, \text { nom }}}\right)\right]
\end{gathered}
$$

where $n, k_{z_{1}}, k_{z_{2}}, f_{z \text {,nom }}, c_{1}, c_{2}$ are tire parameters and $\mu_{i}$ is the coefficient of friction for the i:th tire. In order to determine these parameters, measurements using a flat road-surface simulator have been performed on a set of 225/45R17 tires. The tire parameters have then been adjusted to the tire model given by Eqs. 9-12 Fig. 2 shows the tire measurement data and predicted data with adjusted parameters. Fig. 2a illustrates the non-linear relation between lateral force and side slip, which is also substantially dependent on the tire normal load. As seen in Fig. 2b, the lateral force decreases essentially under the influence of a high longitudinal force; in this paper generated by the in-wheel motor.
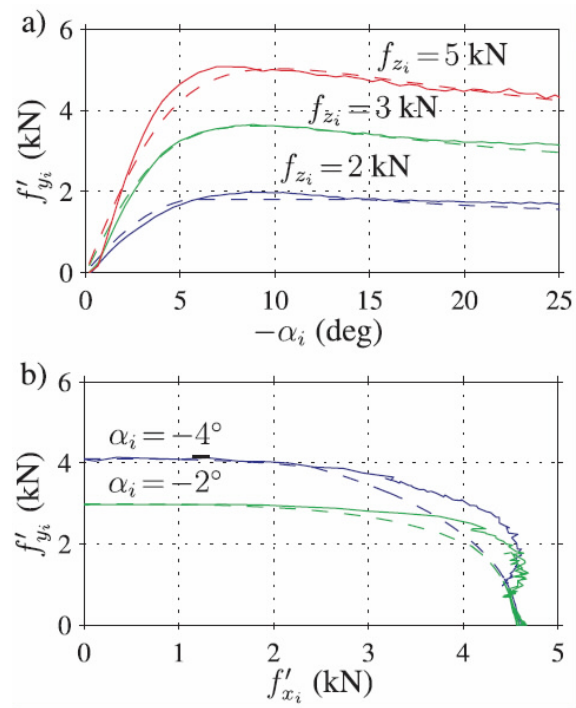

Fig. 2 a) Lateral forces for 2, 3, and $5 \mathrm{kN}$ of vertical load; b) Lateral forces for two side-slip angles at $4 \mathrm{kN}$ vertical load. Solid lines: tire measurements on a 225/45R17 tire; dashed lines: tire model.
An inverse of the tire model given by Eqs. 9-12 is found as

$$
\alpha_{i}=-\frac{1}{B_{y_{i}} \tan \left[\frac{\arcsin \left(f_{y_{i}} / D_{y_{i}}\right)}{C_{y}}\right]},
$$

where $0 \leq\left|f_{y_{i}}\right|<D_{y_{i}}$. The maximum side slip allowed for Eq. 13 to be valid $\left(\alpha_{i, \max }\right)$ is

$$
\alpha_{i, \max }=-\frac{\operatorname{sign}\left(f_{y_{i}}\right)}{B_{y_{i}}} \tan \left(\frac{\pi}{2 C_{y}}\right) .
$$

The inverse given by Eq. 14 limits the side-slip angle to $\alpha_{i, \max }$ where maximum lateral forces are obtained. Thus, the tire is only allowed to generate lateral forces where the slope is positive according to Fig. 2a. Finally, the side-slip angle is, using the vehicle dimensions shown in Fig. 1b, computed as

$$
\alpha_{i}=\arctan \left(\frac{v_{y}+l_{i} \Omega_{z}}{v_{x}}\right)-\delta_{i}, i=1,2,3,4
$$

where $l_{1}=l_{2}=c$ and $l_{3}=l_{4}=-d$.

\subsection{Actuator Dynamics}

For the purpose of steering, it is assumed that each wheel is equipped with two linear actuators positioned under the wheel-hub center. The actuators move symmetrically around the vertical axis of the wheel and can provide steering angles within the interval $\delta_{i} \leq 22^{\square}$. The maximum speed of the steering actuators limits the rotational speed of the wheel to $\pm 1 \mathrm{rad} / \mathrm{s}$. The dynamics of the actuators and the elasticity of the tires are modeled as a first-order filter with a time constant equal to $50 \mathrm{~ms}$.

\section{CLOSED-LOOP VEHICLE CONTROL}

The vehicle movement is considered as following a plane path described by $(v, \beta, \rho)$ where $v$ is the vehicle speed, $\beta$ the vehicle slip and $\rho$ the curvature. Alternatively, the path can also be described by $\left(v_{x}, v_{y}, \Omega_{z}\right)$ where $v_{x}=v \cos \beta, v_{y}=v \sin \beta$ and $\Omega_{z}=\rho v+\dot{\beta}$. Closed-loop vehicle controllers for vehicles equipped with individual force actuation on each corner are elaborated in [3], [4]. A general flow chart of such a controller is shown in Fig. 3.

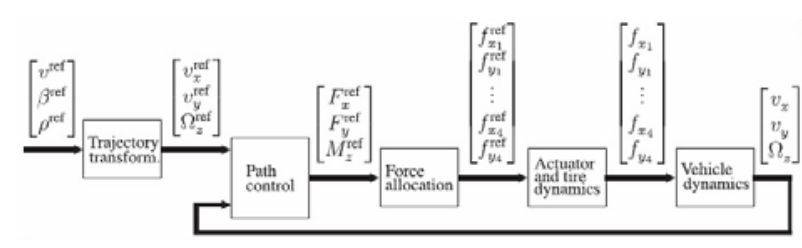

Fig. 3 Flow-chart of the closed-loop vehicle controller. 


\subsection{Design of the Path Controller}

Introducing $s$ as the Laplace variable, the path controller used to minimize the control error, $\mathbf{e}(s)=\mathbf{x}^{\text {ref }}(s)-\mathbf{x}(s)$, can be expressed as

$$
\mathbf{u}=\left(\mathbf{K}_{p}+\frac{\mathbf{K}_{\mathbf{i}}}{s}\right) \mathbf{e}(s)-\mathbf{B}_{a} \mathbf{x}(s)-\mathbf{h}(\mathbf{x}(s)),
$$

where

$$
\mathbf{K}_{p}=\operatorname{diag}\left[k_{p_{1}}, k_{p_{3}}, k_{p_{3}}\right]^{T}
$$

and

$\mathbf{K}_{i}=\operatorname{diag}\left[k_{i_{1}}, k_{i_{3}}, k_{i_{3}}\right]^{T}$ represent three PI controllers.

The term $-\mathbf{h}(\mathbf{x})$ decouples the nonlinear part of Eq. 1, and $\mathbf{B}_{a}=\operatorname{diag}\left[b_{a 1}, b_{a 2}, b_{a 3}\right]^{T}$ represents an inner feedback loop in order to reduce the controller's sensitivity to the disturbance $\mathbf{v}(\mathbf{x})$. Inserting Eq. 16 in Eq. 1, the transfer-function matrices that represent the closed-loop $\mathbf{G}_{\mathrm{cl}}(s)$ and sensitivity $\mathbf{S}(s)$ are found as

$$
\begin{aligned}
\mathbf{x}(s) & =\underbrace{\left(\mathbf{M} s+\mathbf{B}_{a}+\mathbf{K}_{p}+\frac{\mathbf{K}_{\mathbf{i}}}{s}\right)^{-1}\left(\mathbf{K}_{p}+\frac{\mathbf{K}_{\mathbf{i}}}{s}\right)}_{\mathbf{G}_{\mathrm{cl}}(s)} \mathbf{x}^{\mathrm{ref}}(s) \\
& +\underbrace{\left(\mathbf{M} s+\mathbf{B}_{a}+\mathbf{K}_{p}+\frac{\mathbf{K}_{\mathbf{i}}}{s}\right)^{-1}}_{\mathbf{S}(s)} \mathbf{v}(s) .
\end{aligned}
$$

The controller parameters $\mathbf{K}_{p}, \mathbf{K}_{i}$ and $\mathbf{B}_{a}$ are now chosen are now chosen as

$$
\begin{gathered}
\mathbf{K}_{p}=\operatorname{diag}\left[\alpha_{\text {long }} m, \alpha_{\text {lat }} m, \alpha_{\text {yaw }} J_{z}\right], \\
\mathbf{B}_{a}=\mathbf{K}_{p}, \quad \mathbf{K}_{i}=\operatorname{diag}\left[\alpha_{\text {long }}^{2} m, \alpha_{\text {lat }}^{2} m, \alpha_{\text {yaw }}^{2} J_{z}\right],
\end{gathered}
$$

where $\alpha_{\text {long }}, \alpha_{\text {lat }}$ and $\alpha_{\text {yaw }}$ represent the desired bandwidths of the longitudinal speed, lateral speed and yaw rate controllers. The resulting closed-loop and sensitivity functions become (neglecting tire and actuator dynamics)

$$
\begin{gathered}
\mathbf{G}_{\mathrm{cl}}(s)=\operatorname{diag}\left[\frac{\alpha_{\text {long }}}{s+\alpha_{\text {long }}}, \frac{\alpha_{\text {lat }}}{s+\alpha_{\text {lat }}}, \frac{\alpha_{\text {yaw }}}{s+\alpha_{\text {yaw }}}\right], \\
\mathbf{S}(s)=\operatorname{diag}\left[\frac{\mathrm{s}}{m\left(\mathrm{~s}+\alpha_{\text {long }}\right)^{2}}, \frac{\mathrm{s}}{m\left(\mathrm{~s}+\alpha_{\text {lat }}\right)^{2}}, \frac{\mathrm{s}}{J\left(\mathrm{~s}+\alpha_{\text {yaw }}\right)^{2}}\right]
\end{gathered}
$$

The controller design adopted here is based on the principle of internal model control [16] together with an inner feedback loop to reduce the impact of the disturbance $\mathbf{v}(\mathbf{x})$. As seen, by choosing the control parameters according to Eqs. 18-19, the desired bandwidths are reached. Note also that the controller parameters are expressed directly in model parameters and the desired bandwidth. Hence, the tuning procedure of the controller is simplified.

\subsection{Force Allocation}

The outputs of the path controller are the global forces $F_{x}^{\mathrm{ref}}, F_{y}^{\mathrm{ref}}$ and $M_{z}^{\mathrm{ref}}$. Hence, these forces must be allocated properly to the in-wheel motors and actuators. This can be achieved in an infinite number of ways; an approach using an optimization algorithm is proposed in [5] where an allocation is achieved that maximizes the tire's grip potential. In this paper, focus is put on vehicle behavior during faults and a simpler allocation is adopted as follows:

$$
\begin{aligned}
& \left(\begin{array}{l}
f_{x_{1}}^{\mathrm{ref}} \\
f_{x_{2}}^{\mathrm{ref}}
\end{array}\right)=\left(\begin{array}{c}
f_{x_{3}}^{\mathrm{ref}} \\
f_{x_{4}}^{\mathrm{ref}}
\end{array}\right)=\left(\begin{array}{cc}
-2 a & 2 b \\
2 & 2
\end{array}\right)^{-1}\left(\begin{array}{c}
k M_{z}^{\mathrm{ref}} \\
F_{x}^{\mathrm{ref}}
\end{array}\right), \\
& \left(\begin{array}{c}
f_{y_{1}}^{\mathrm{ref}} \\
f_{y_{3}}^{\mathrm{ref}}
\end{array}\right)=\left(\begin{array}{c}
f_{y_{2}}^{\mathrm{ref}} \\
f_{y_{4}}^{\mathrm{ref}}
\end{array}\right)=\left(\begin{array}{cc}
2 c & -2 d \\
2 & 2
\end{array}\right)^{-1}\left(\begin{array}{c}
k M_{z}^{\mathrm{ref}} \\
F_{x}^{\mathrm{ref}}
\end{array}\right) .
\end{aligned}
$$

As seen, the longitudinal forces are distributed equally to the front and rear of the vehicle. The same holds for the lateral forces that are distributed equally to the left and right sides of the vehicle. The parameter $k$ determines the amount of yaw moment that is generated from the longitudinal and lateral corner forces, respectively. This parameter, together with Eqs. 22-23 turns the allocation formulation into an exactly determined solution.

\section{ELECTRICAL SETUP}

Fig. 4 shows a schematic view of the electric driveline for the considered vehicle. The inverters are powered by a common battery and a super/ultra capacitor which is connected to the battery through a $\mathrm{dc} / \mathrm{dc}$ converter of buck/boost type.

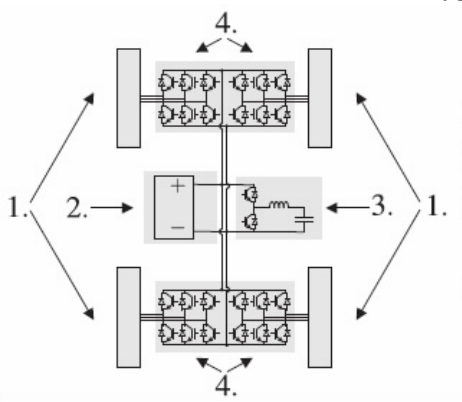

1. In-wheel motor

2. Battery

3. Supercapacitor and dc/dc converter

4. Voltage source inverter

Fig. 4 Schematic view of the electric driveline for the considered vehicle.

\subsection{Inverter Shutdown}

The fault type considered in this paper is referred to as an inverter shutdown [18]. Here, the control signals to the transistor switches, for some reason, vanish. Reasons for the origin of such a fault include failure of the gate drive (supplying the gate pulses to any, or all, of the switches), a signal-cable breakdown and loss of power to the control circuitry.

Below a certain speed, the induced voltage originating from the permanent magnets is lower than the dc-side voltage and no current will flow through the diodes of the inverter. Hence, the output torque is zero. At higher speeds, i.e., when field-weakening is applied, 
the induced voltage can be higher than the dc-side voltage. This produces a braking torque which, depending on the capacity of the dc side to absorb the generated power, can entail the risk of damage to the inverter. If the dc side cannot absorb (or redirect) the generating power from the faulted drive, the dc-side voltage may rapidly increase, entailing the risk of permanent damage to the dc source and/or inverter. The seriousness of such a fault may motivate the need of increasing the inverter voltage rating or adding means to absorb this power using an additional brake resistor. For vehicles equipped with super/ultra capacitors, the capacity to quickly absorb the generating power (and thereby maintain the dc side voltage constant) during an inverter shutdown can be very high, especially since they are typically not fully charged at high speeds in order to absorb energy during subsequent braking. Therefore, it is assumed in this paper that the dc-side voltage is essentially constant even after an inverter shutdown.

The steady-state braking torque of a $30 \mathrm{~kW}$ in-wheel motor has been obtained experimentally using a $200 \mathrm{~V}$ dc-side voltage. To predict the braking torque at other voltages, the analytical method presented in [18] is compared with simulations using the, well-known PMSM model expressed in the rotor-fixed coordinate system, here termed dq-model (see, e.g., [19]). The predicted steady-state braking torques along with measurement data are shown in Fig. 5a. As seen, the latter model yields a better agreement with the experimental data. Fig. $5 \mathrm{~b}$ shows the generated torque and predicted tire force during an inverter shutdown at $\omega=60 \mathrm{rad} / \mathrm{s}$; using the dynamic dq-model of the PMSM and its corresponding steady-state model. Due to the elasticity of the tire, the difference in tire force of the two models is minor and for this reason, the steady-state model is used in the case study in order to reduce the simulation time.
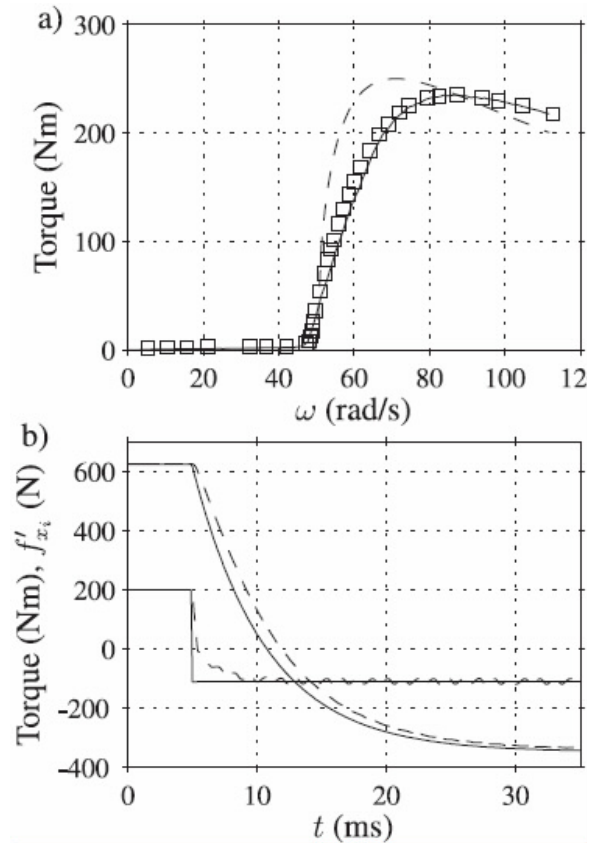

Fig. 5 a) Steady-state braking torque for a $30 \mathrm{~kW}$ in-wheel motor. Solid line: transient dq-model, dashed line: analytical model according to $[18]$, squares $(\square)$ : measurement. b) Generated torque and tire forces during an inverter shutdown at $\omega=60 \mathrm{rad} / \mathrm{s} \mathrm{using}$ steady-state (solid lines) and transient (dashed lines) dq-models.

Remark: If a gate drive, controlling the gate pulses of one specific phase leg of the inverter fails, results in [11] show that the preferred fault-handling strategy is to remove the gate pulses from all inverter switches, which effectively results in the case described above.

\section{CASE STUDY}

The path controller has been evaluated in a number of fault scenarios and two demonstrative scenarios are presented here. The vehicle and in-wheel motor data, along with the control parameters, are found in the Appendix. For purpose of comparison, simulation results are also included where the path controller is not activated, i.e., constant steering angles and motor torques are assumed (except, of course, for the faulted in-wheel motor).

\subsection{High-Speed Straight Ahead Driving at Low $\mu$ Conditions}

Here, the vehicle drives along a straight road with the reference speed $v^{\text {ref }}=33.3 \mathrm{~m} / \mathrm{s} \quad(120 \mathrm{~km} / \mathrm{h})$. A snowy road condition is assumed and $\mu$ is set to $\mu=0.2$. At $t=1 \mathrm{~s}$, one or two inverters, controlling either a single in-wheel motor or both of the front (or rear) motors, shut down. The results shown here correspond to the case when the inverter controlling the rear left in-wheel motor shuts down which, identical to a shutdown of the rear-right inverter, is the most severe case in terms of lateral displacement. Due to the high speed, the faulted in-wheel motor generates power into the dc side and a braking torque is produced. Fig. 6a shows resulting vehicle speeds $\left(v_{x}, v_{y}\right.$, and $\left.\Omega_{z}\right)$ using the closed-loop path controller and, for comparison, if the steering angles and motor torques are kept constant. As seen, when using the path controller the vehicle speeds are only slightly affected which practically eliminates a large drift from the desired trajectory. The resulting steer and slip angles using the implemented path controller are shown in Fig. $6 \mathrm{~b}$.

\subsection{High-Speed Curve Driving at Nominal $\mu$ Conditions}

To investigate the vehicle behavior when a fault occurs during high-speed curve driving, the following scenario is studied. The vehicle is following a desired left-turn curve trajectory with a radius of $250 \mathrm{~m}$ at constant $\operatorname{speed} v^{\text {ref }}=33.3 \mathrm{~m} / \mathrm{s}(120 \mathrm{~km} / \mathrm{h})$ and dry road conditions are assumed $(\mu=0.2)$. At $t=1 \mathrm{~s}$, the rear-left inverter shuts down. Fig. 7a shows the resulting vehicle 
speeds when using the path controller and also when the steering angles and motor torques are kept constant.

The resulting steer and slip angles and tire forces when using the path controller are shown in Fig. $7 \mathrm{~b}$ and Fig. 8 respectively. Here too, the path controller, by controlling the steering angles and motor torques on the individual wheels, manages to maintain the vehicle speeds with only slight deviations from their pre-fault values. Without the path controller, the vehicle speeds deviate quickly from their desired values if the correct counter-action is not taken by the driver.
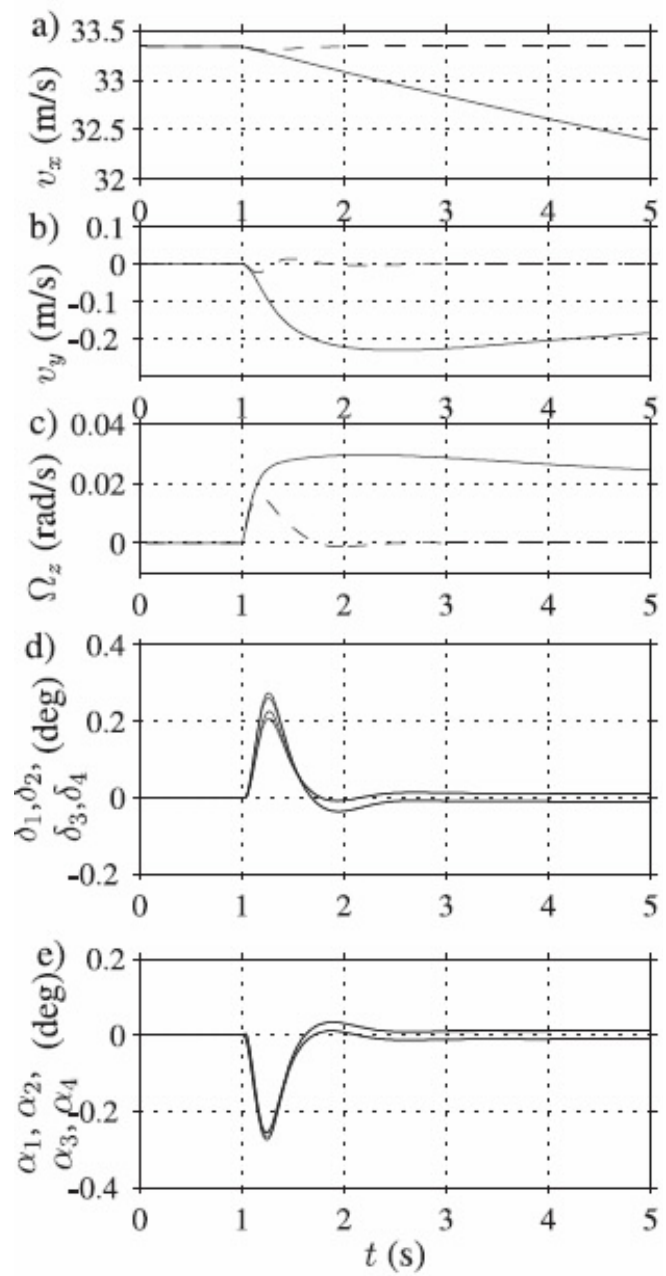

Fig. 6 a)-c) Vehicle speeds during a fault of the rear-left inverter at $t=1 \mathrm{~s}$ during a straight-ahead driving situation. Solid lines: uncontrolled case; dashed lines: using the path controller. d)-e) Resulting steer and slip angles when using the path controller.
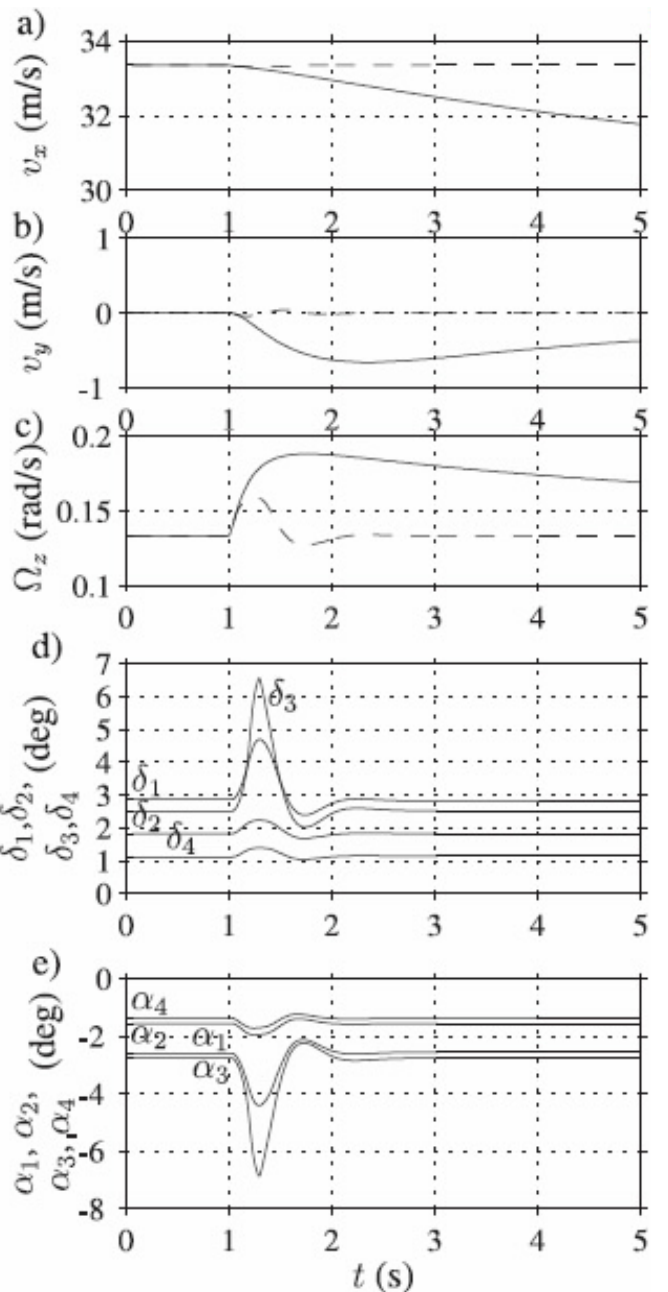

Fig. 7 a)-c) Vehicle speeds in longitudinal, lateral, and yaw directions during a fault of the rear-left in-wheel motor at $t=1 \mathrm{~s}$ during high-speed curve driving. Solid lines: uncontrolled case; dashed lines: using the path controller. d)-e) Resulting steer and slip angles when using the path controller. 

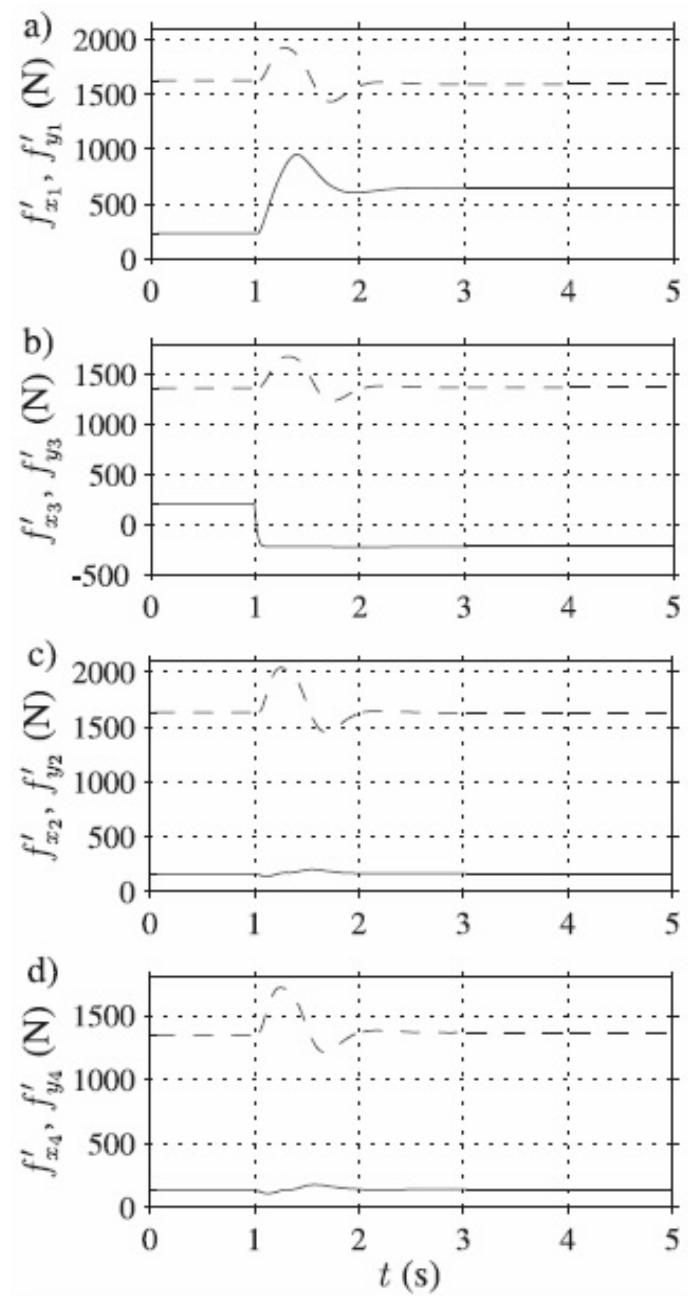

Fig. 8 a)-d) Resulting tire forces using the path controller during high-speed curve driving. Solid lines: $f_{x}^{\prime}$; dashed lines: $f_{y}^{\prime}$.

\section{CONCLUSIONS}

This paper has presented an analysis of the stability of an electric vehicle equipped with in-wheel motors during an important class of electrical faults. The analysis was carried out in the form of a case study using experimental tire measurement data and measurements on an existing $30 \mathrm{~kW}$ in-wheel motor. The case study demonstrated that the stability of the vehicle can be seriously degraded when the electrical fault occur. However, by using a modified variant of the path controller suggested in [3] with a simple method to allocate the forces on each wheel, vehicle stability could be maintained. This inherent capacity to handle an important class of electrical faults is attractive, especially since no additional fault-handling strategy or hardware is needed. Future research will study to what extent more advanced wheel-force allocation methods function during different types of fault conditions.

\section{APPENDIX}

TABLE I

VEHICLE AND IN-WHEEL MOTOR DATA.

\begin{tabular}{|c|c|c|}
\hline \multicolumn{3}{|l|}{ Vehicle parameters } \\
\hline Vehicle mass & $m$ & $1300 \mathrm{~kg}$ \\
\hline Yaw inertia & $I_{z}$ & $1100 \mathrm{kgm}^{2}$ \\
\hline Vehicle dimensions & $\{a, b\}$ & $\{0.7,0.7\} \mathrm{m}$ \\
\hline Vehicle dimensions & $\{c, d\}$ & $\{1.1,1.3\} \mathrm{m}$ \\
\hline Height to center of gravity & $\kappa$ & $0.5 \mathrm{~m}$ \\
\hline Roll resistance coeff. & $f_{\mathrm{r}}$ & 0.012 \\
\hline Frontal area & $A_{\mathrm{f}}$ & $1.5 \mathrm{~m}^{2}$ \\
\hline Coefficient of drag & $C_{d}$ & 0.35 \\
\hline \multicolumn{3}{|l|}{ Wheels and tires } \\
\hline Tire dimension & 225/45R17 & \\
\hline Wheel radius & $r_{\mathrm{w}}$ & $0.32 \mathrm{~m}$ \\
\hline Steering angle limit & & $\pm 22^{\circ}$ \\
\hline Nominal wheel load & $F_{z, \text { nom }}$ & $3300 \mathrm{~N}$ \\
\hline Shape factor & & 1.66 \\
\hline Tire model parameters & $\left\{c_{1}, c_{2}, n\right\}$ & $\{21.2,2.2,3.0\}$ \\
\hline Tire model parameters & $\left\{k_{z_{1}}, k_{z_{2}}\right\}$ & $\{1.0,0.15\}$ \\
\hline \multicolumn{3}{|l|}{ In-wheel motor parameters } \\
\hline Rotor-magnet configuration & $\begin{array}{l}\text { Outer rotor, } \\
\text { surface mounted }\end{array}$ & \\
\hline No. of pole pairs & $n_{p}$ & 8 \\
\hline Stator resistance & & $160 \mathrm{~m} \Omega$ \\
\hline$d$ - and $q$-axis inductances & $\left\{L_{d}, L_{q}\right\}$ & $\{2.5,2.9\} \mathrm{mH}$ \\
\hline $\begin{array}{l}\text { flux linkage } \\
\text { flination }\end{array}$ & $\psi_{m}$ & $318 \mathrm{mWb}$ \\
\hline \multicolumn{3}{|l|}{ Vehicle control parameters } \\
\hline Allocation ratio & $k$ & 0.9 \\
\hline Desired bandwidths & $\left\{\alpha_{\text {long }}, \alpha_{\text {lat }}, \alpha_{\text {yaw }}\right\}$ & $\{1,1,1\} \mathrm{rad} / \mathrm{s}$ \\
\hline
\end{tabular}

\section{ACKNOWLEDGEMENT}

This work was supported in part by the Swedish National Energy Agency within the "Energy Systems in Road Bound Vehicles" research programme.

\section{REFERENCES}

[1] S. Sakai, H. Sado, and Y. Hori, "Motion control in an electric vehicle with four independently driven in-wheel motors," IEEE/AMSE Trans. Mechatronics., vol. 4, no. 1, pp. 9-16, 1999.

[2] Y. Hori, "Future vehicle driven by electricity and control - research on four-wheel-motored "UOT Electric March II," IEEE Trans. Ind. Electron., vol. 51, no. 5, pp. 954-962, 2004. [3] J. Fredriksson, J. Andreasson, and L. Laine, "Wheel force distribution for improved handling in a hybrid electric vehicle using nonlinear control," in Proc. 43rd IEEE Conf. on Decision and Control, vol. 4, 2004, pp. 4081-4086.

[4] R. Orend, "Modelling and control of a vehicle with single chassis actuators," in Proc. 16th IFAC World Congress, 2005. [5] J. Andreasson and T. Bünte, "Global chassis control based on inverse vehicle dynamics models," Vehicle System Dynamics, vol. 44, Supplement, 2006.

[6] Z. Rahman, M. Ehsani, and K. L. Butler, "Effect of motor short circuit on EV and HEV traction systems," in Proc. SAE Future Transportation Tech. Conf., no. 2000-01-3063, 2001.

[7] P. H. Mellor, T. J. Allen, R. Ong, and Z. Rahman, "Faulted behaviour of permanent magnet electric vehicle traction drives," in Proc. IEEE IEMDC'03, vol. 1, 2003, pp. 554-558. [8] B. A. Welchko, T. M. Jahns, W. L. Soong, and J. M. Nagashima, "IPM synchronous machine drive response to symmetrical and asymmetrical short circuit faults," IEEE Trans. Energy Conversion, vol. 18, no. 2, pp. 291-298, 2003. [9] N. Bianchi, S. Bolognani, and M. Zigliotto, "Analysis of PM motor synchronous motor drive failures during flux 
weakening operation," in Proc. IEEE 27th Annu. Power Electron. Specialists Conf., vol. 2, 1996, pp. 1542-1548.

[10] C. Gerada, K. Bradley, and M. Sumner, "Winding turn-to-turn faults in permanent magnet synchronous machine drives," in Conf. Rec. IEEE 40th IAS Annu. Meeting, vol. 2, 2005, pp. 1029-1036.

[11] B. A. Welchko, T. M. Jahns, and S. Hiti, "IPM synchronous machine drive response to a single-phase open circuit fault," IEEE Trans. Power Electron., vol. 17, no. 5, pp. 764-771, 2002.

[12] H. Miyazaki and T. Ohmae, "Driving stability for electric vehicle with independently driven two wheels in case of inverter failure," in Conf. Rec. Eur. Conf. on Power Electron. and Applicat., 2005.

[13] S. Zetterström, "Electromechanical steering, suspension, drive and brake modules," in Proc. IEEE 56th Vehicular Technol. Conf., vol. 3, 2002, pp. 1856-1863.

[14] M. Jonasson, S. Zetterström, and A. S. Trigell, "Autonomous corner modules as an enabler for new vehicle chassis solutions," in Conf. Rec. FISITA World Automotive Congress, 2006.

[15] H. B. Pacejca, Tyre and Vehicle Dynamics. Oxford, United Kingdom: Butterworth-Heinmann, 2002.

[16] M. Morari and E. Zafiriou, Robust Process Control. Englewood Cliffs, NJ: Prentice-Hall, 1989.

[17] L. Harnefors, K. Pietiläinen, and L. Gertmar, "Torque-maximizing field-weakening control: design, analysis, and parameter selection," IEEE Trans. Ind. Electron., vol. 48, no. 1, pp. 161-168, 2001.

[18] T. M. Jahns and V. Caliskan, "Uncontrolled generator operation of interior PM synchronous machines following high-speed inverter shutdown," IEEE Trans. Ind. Applicat., vol. 35, no. 6, pp. 1347-1357, 1999.

[19] A. E. Fitzgerald, C. Kingsley, Jr, and S. D. Umans, Electric Machinery, Fifth Edition. London, United Kingdom: McGraw-Hill, 1992.

\section{BIOGRAPHIES ${ }^{1}$}

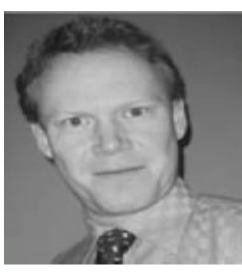

Mats Jonasson has been employed at Volvo Car Cooperation since 1998. His experience is in design engineering and he has a M.Sc. degree in electrical engineering, but now he works as a Ph.D. candidate in the department of Chassis and Vehicle Dynamics at Volvo Car Cooperation in Göteborg, Sweden. His research covers autonomous corner modules, in cooperation with KTH Vehicle Dynamics, Stockholm, Sweden.

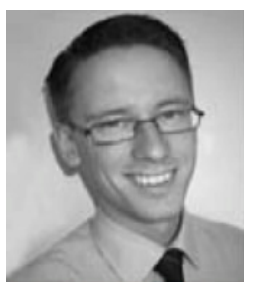

Oskar Wallmark received the Ph.D. degree in 2006 from Chalmers University of Technology, Göteborg, Sweden. He is currently working as a researcher within the Swedish Center of Excellence in Electric Power Engineering $\left(\mathrm{EKC}^{2}\right)$ at the Royal Institute of Technology $(\mathrm{KTH})$ in Stockholm, Sweden. His research interests include control and analysis of electric drives, particularly in hybrid and electric vehicle applications.

\footnotetext{
1 The contributions from the individual authors are equal.
} 